\title{
Effect of sodium on bioactive sol-gel-derived borate glasses
}

\author{
William C. Lepry, Sophia Smith, Showan N. Nazhat* \\ Department of Mining and Materials Engineering, McGill University, Montreal, QC, Canada
}

\begin{abstract}
A B S T R A C T
Bioactive, sol-gel derived borate glasses (SGBGs) can rapidly convert to hydroxy-carbonated apatite (HCA) in simulated body fluid (SBF). The processing conditions and compositional changes in four-component glasses have previously been investigated, yet the effect of certain elements, such as sodium, on the processing and bioactivity has not been explored. Therefore, in this study, a borate substituted Bioglass ${ }^{\circledast}$ "45S5" of the formulation $(46.1) \mathrm{B}_{2} \mathrm{O}_{3}-(26.9) \mathrm{CaO}^{-}(24.4) \mathrm{Na}_{2} \mathrm{O}-(2.6) \mathrm{P}_{2} \mathrm{O}_{5} ; \mathrm{mol}$ $\%$, was created as the baseline glass and the amount of sodium was incrementally decreased three times, while maintaining the ratio of the other elements, until a sodium-free, three-component composition was generated $(61.0) \mathrm{B}_{2} \mathrm{O}_{3}-(35.6) \mathrm{CaO}-(3.4) \mathrm{P}_{2} \mathrm{O}_{5}$; mol\%. Decreasing sodium content altered the gelation behaviour, textural properties, and greatly influenced reactivity as measured through gravimetric changes when exposed to water vapour. Furthermore, ion release profiles corresponded with the different glass compositions, however, interestingly, sodium content had very little effect on rate of conversion to HCA in SBF, which was observed to be within $2 \mathrm{~h}$, according to x-ray diffraction, attenuated total reflectance-Fourier-transform infrared spectroscopy, and scanning electron microscopy. This study aims to serve as a basis to develop more simplified SGBG systems for tissue engineering applications.
\end{abstract}

\section{Introduction}

The ability for glasses to form a surface, bone mineral-like, hydroxycarbonated apatite (HCA) layer after submersion in physiological fluids ("bioactivity") was first discovered in silicate systems [1, 2]. During this process [3], the glass releases ions which play a key role in HCA conversion that can lead to the direct integration with native bone tissue. The release of these ions has also been recently implicated in soft tissue engineering applications [4] since they can stimulate the body's natural healing processes, thereby expanding the classical definition of bioactivity for glasses [3, 5]. Compared to silicate-based glasses, bioactive borate glasses have lower chemical durability, which can allow for a more rapid and complete conversion to HCA [6-11]. During this process, these glasses exhibit the "volume reduction" model where the HCA is deposited directly on the surface of the glass and continues towards the core until none of the original glass remains [7]. The more rapid ion release and ability to fully convert has also made bioactive borate glasses prime candidates for soft tissue engineering applications, such as wound healing [12-15].

Regardless of composition, most bioactive glasses are traditionally generated through the melt-quench process, which involves the high temperature melting of oxides followed by their rapid cooling ("quenching") to preserve the amorphous structure. With the advent of the sol-gel process; a robust, low temperature, aqueous based processing approach, it has been possible to create bioactive glasses with orders of magnitude higher specific surface area values [16]. This process typically uses a mixture of metal alkoxide precursors to form a colloidal suspension of particles in a liquid (the "sol"), which then undergo hydrolysis and condensation reactions to form a "gel"; essentially the glass network [17]. This gel then undergoes drying and heat treatment (calcination) to eliminate excess precursor organic materials and to densify the glass structure while still maintaining high specific surface areas and porosities.

From a biomedical application prospective, sol-gel derived glasses offer distinct advantages when compared to their melt-quench derived equivalents. For example, the increased surface area and porosity values allow for more rapid ion release rates and thus increased conversion rates to HCA $[18,19]$ and expanded the bioactive silicate-glass compositional range up to $90 \mathrm{~mol} \% \mathrm{SiO}_{2}$ compared to the melt-quench derived limit of $\sim 60 \mathrm{~mol} \% \mathrm{SiO}_{2}$ [16]. Furthermore, it is possible to achieve higher homogeneity due to the precursor materials and the processing temperatures are lower. Thus, fluxes such as sodium, which was originally added to bioactive glass compositions to make melting and homogenization easier, maintain a physiological balance of sodium at the glass-HCA interface and modify the local $\mathrm{pH}$ in the implant vicinity [5], are not necessary in the sol-gel process [19]. Since then, numerous ternary sol-gel glasses excluding sodium have been created [20].

Nonetheless, Chen et al. recently created the first sol-gel derived Bioglass ${ }^{\circledR}$ "45S5" [(46.1) $\mathrm{SiO}_{2}-(26.9) \mathrm{CaO}-(24.4) \mathrm{Na}_{2} \mathrm{O}-(2.6) \mathrm{P}_{2} \mathrm{O}_{5}$ (mol $\%)$ ] with sodium in order to increase the mechanical properties while creating a more biodegradable crystalline phase [21]. The addition of sodium as a network modifier and creates more non-bridging oxygens, thus lowering the chemical durability and increasing the

\footnotetext{
* Corresponding author.

E-mail address: showan.nazhat@mcgill.ca (S.N. Nazhat).
} 
biodegradability. After calcination, the resultant glasses were semicrystalline, which commonly occurs with other sol-gel derived "45S5" glasses [22-26]. This is mainly due to the requirement of reaching high enough calcination temperatures to eliminate the precursor nitrates. A 45S5-like composition [(49.2) $\mathrm{SiO}_{2}-(25.8) \mathrm{CaO}-(23.3) \mathrm{Na}_{2} \mathrm{O}-(1.7) \mathrm{P}_{2} \mathrm{O}_{5}$ $(\mathrm{mol} \%)]$ has also been reported to partially crystallize after calcination [27]. Despite this, amorphous versions of this glass composition have been reported in literature through adjustments in precursor materials, processing routes, and most importantly, calcination temperatures [28-30].

Although, sol-gel derived glasses with borate as the main component have been far less studied [31-34], the first reported composition, (80) $\mathrm{B}_{2} \mathrm{O}_{3}-(20) \mathrm{Na}_{2} \mathrm{O}$ (mol\%), incorporated sodium [35]. These glasses, however, were not made with the intent of biomedical applications. Borate has also been added to bioactive, sol-gel silicate- [36, 37] and phosphate-glasses $[38,39]$ as a modifier to help improve the mechanical and bioactivity properties. Furthermore, we have previously reported on a wide compositional range of highly bioactive sol-gel derived borate glasses (SGBGs, 36-61 mol\% $\mathrm{B}_{2} \mathrm{O}_{3}$ ) [40] based on variations of a borate substituted, "45S5" composition whose meltquench derived composition has been previously studied [7, 41]. These glasses demonstrated specific surface areas and porosities at least two orders of magnitude greater than the melt-quench equivalent leading to a 25-fold increase in HCA conversion rate. Recently, we have also shown that similar sodium-containing SGBG compositions, can be produced using a variety sol-gel precursors and processing parameters while still maintaining their high bioactivity; converting to HCA within $2 \mathrm{~h}$ according to $\mathrm{x}$-ray diffraction [42]. However, while it is known that sodium is not needed for bioactive silicate sol-gel glasses, there has yet to be a systematic study reporting on the effect of sodium content on the properties of SGBGs. Therefore, this study examined the effect of incrementally decreasing the sodium content on the processing, structural, reactivity, and bioactivity properties of these glasses.

\section{Experimental}

\subsection{Materials and methods}

Table 1 gives an overview of the SGBG compositions investigated in this study. The baseline composition was a previously examined [40, 42] borate substituted Bioglass ${ }^{\circledR}$ (Na24) [(46.1) $\mathrm{B}_{2} \mathrm{O}_{3}-(26.9) \mathrm{CaO}-(24.4)$ $\left.\mathrm{Na}_{2} \mathrm{O}-(2.6) \mathrm{P}_{2} \mathrm{O}_{5} ; \mathrm{mol} \%\right]$, and the amount of sodium was incrementally decreased by $\approx 8 \mathrm{~mol} \%$, while maintaining the ratios of the remaining components, until a three component, sodium-free SGBG composition $(\mathrm{Na0})\left[(61.0) \mathrm{B}_{2} \mathrm{O}_{3}-(35.6) \mathrm{CaO}-(3.4) \mathrm{P}_{2} \mathrm{O}_{5} ; \mathrm{mol} \%\right]$ was generated.

The glasses were fabricated based on a previously described method [40]. Briefly, boric acid ( $\geq 99.5 \%)$ and anhydrous ethanol (Sigma Aldrich, Canada) were mixed and magnetically stirred in a watch glasscovered Teflon beaker at $40 \pm 3{ }^{\circ} \mathrm{C}$ to aid dissolution. Once the solution became clear, triethyl phosphate ( $>99.8 \%$; Fisher Scientific, Canada), calcium methoxyethoxide (20\% in methoxyethanol; Gelest, USA), and sodium methoxide ( $25 \mathrm{wt} \%$ in methanol; Fisher Scientific, Canada) were added in a drop wise manner at $30 \mathrm{~min}$ intervals. Once the final addition was complete, the sol was mixed for an additional 30 min or until gelation occurred, followed by transferring into sealed polypropylene vials, and aged at $37^{\circ} \mathrm{C}$ for 10 days. The gels were then

Table 1

SGBG Compositions and Codes (mol\%).

\begin{tabular}{llllll}
\hline $\mathrm{ID}$ & $\mathrm{B}_{2} \mathrm{O}_{3}$ & $\mathrm{CaO}$ & $\mathrm{P}_{2} \mathrm{O}_{5}$ & $\mathrm{Na}_{2} \mathrm{O}$ & $\% \mathrm{CaO}+\mathrm{Na}_{2} \mathrm{O}$ \\
\hline $\mathrm{Na} 24$ & 46.1 & 26.9 & 2.6 & 24.4 & 51.3 \\
$\mathrm{Na} 16$ & 51.1 & 29.8 & 2.9 & 16.3 & 46.1 \\
$\mathrm{Na} 8$ & 56.0 & 32.7 & 3.2 & 8.1 & 40.8 \\
$\mathrm{Na} 0$ & 61.0 & 35.6 & 3.4 & 0 & 35.6 \\
\hline
\end{tabular}

transferred to crystallization dishes and dried in air at room temperature (RT) for 1 day, followed by oven drying at $120^{\circ} \mathrm{C}$ for 2 days. Finally, a calcination step was undertaken at $400^{\circ} \mathrm{C}$ at a rate of $3{ }^{\circ} \mathrm{C} / \mathrm{min}$, with a $2 \mathrm{~h}$ dwell period, followed by furnace cooling. The calcined glasses were then ground to a particle size fraction of $25-75 \mu \mathrm{m}$ and stored in a desiccator until analysis.

\subsection{Glass particle characterization}

The average particle size $\left(D_{\text {avg }}\right)$ and median diameter $\left(D_{50}\right)$ of the glass powders was determined using a Horiba LA-920 (ATS Scientific Inc., Canada). The specific surface area (SSA) was measured with nitrogen gas adsorption and desorption isotherms collected with a Micromeritics TriStar 3000 (Micromeritics Instrument Corporation, USA) gas sorption system $(\mathrm{n}=3)$. SSA values were determined using the Brunauer-Emmett-Teller (BET) method [43] while the average pore width and pore volume were calculated using the Barrett-Joyner-Halenda (BJH) method [44].

\section{3. $X$-ray diffraction $(X R D)$}

XRD diffractograms of the glasses were analyzed using a Bruker D8 Discover X-ray diffractometer (Bruker AXSS Inc., USA) equipped with a CuKa $(\lambda=0.15406 \mathrm{~nm})$ target set to a power level of $40 \mathrm{mV}$ and $40 \mathrm{~mA}$. Three frames were collected from 10 to 702 theta $\left(^{\circ}\right)$, using an area detector, and merged in post processing while phase identification was carried out using X'Pert Highscore Plus (PANalytical, Netherlands).

\subsection{Attenuated total reflectance-Fourier transform infrared spectroscopy (ATR-FTIR)}

ATR-FTIR spectroscopy was carried out between 4000 and $650 \mathrm{~cm}^{-1}$ with a resolution of $4 \mathrm{~cm}^{-1}$ using 64 scans per sample using a Spectrum 400 (Perkin-Elmer, USA). The collected spectra were baseline corrected then normalized to the total area surface area under absorption bands using Spectrum software (Perkin-Elmer, USA).

\subsection{Scanning electron microscopy (SEM)}

SEM was carried out on Pt sputter coated samples. Analysis was performed with an Inspect F50 Field Emission Scanning Electron Microscope (FEI Corporation, U.S.A.) at $5 \mathrm{kV}$.

\subsection{Reactivity}

The aqueous interactions of SGBG particles were investigated through dynamic vapour sorption (DVS) using a DVS Intrinsic (Surface Measurement Systems Ltd., U.K.), which measures mass changes $( \pm 0.1 \mu \mathrm{g}$ ) under controlled relative humidity $(\mathrm{RH})$ and temperature. Approximately $5 \mathrm{mg}$ of glass powder were placed in an aluminum pan and inserted into a chamber at $37 \pm 0.05^{\circ} \mathrm{C}$ which were then directly exposed to $90 \% \mathrm{RH}$ for $6 \mathrm{~h}$ and then to $0 \% \mathrm{RH}$ for a further $6 \mathrm{~h}$.

\subsection{Inductively coupled plasma-optical emission spectrometry (ICP-OES)}

The release of boron, calcium, sodium, and phosphorus ions from glass powders $(\mathrm{n}=3)$ at a $1.5 \mathrm{mg} / \mathrm{mL}$ ratio in deionized water (DIW), was quantified using an inductively coupled plasma-optical emission spectrophotometer (Thermo Scientific iCAP 6500, USA). Collected aliquots at $0.5,6$, and $24 \mathrm{~h}$ were filtered through a $0.2 \mu \mathrm{m}$ nylon filter then stored in a $15 \mathrm{~mL}$ falcon tube followed by dilution with $4 \%(\mathrm{w} / \mathrm{v})$ nitric acid (Fisher Scientific, Canada). Serially diluted solutions of boron (0.5, $5,50 \mathrm{ppm})$, calcium $(0.2,2,20 \mathrm{ppm})$, sodium $(1,10,100)$ and phosphorous $(0.1,1,10 \mathrm{ppm})$ were used as standards. Furthermore, the $\mathrm{pH}$ change of the solution due to glass dissolution at the same timepoints was measured $(\mathrm{n}=3)$ with an Accumet XL20 pH meter (Fisher 


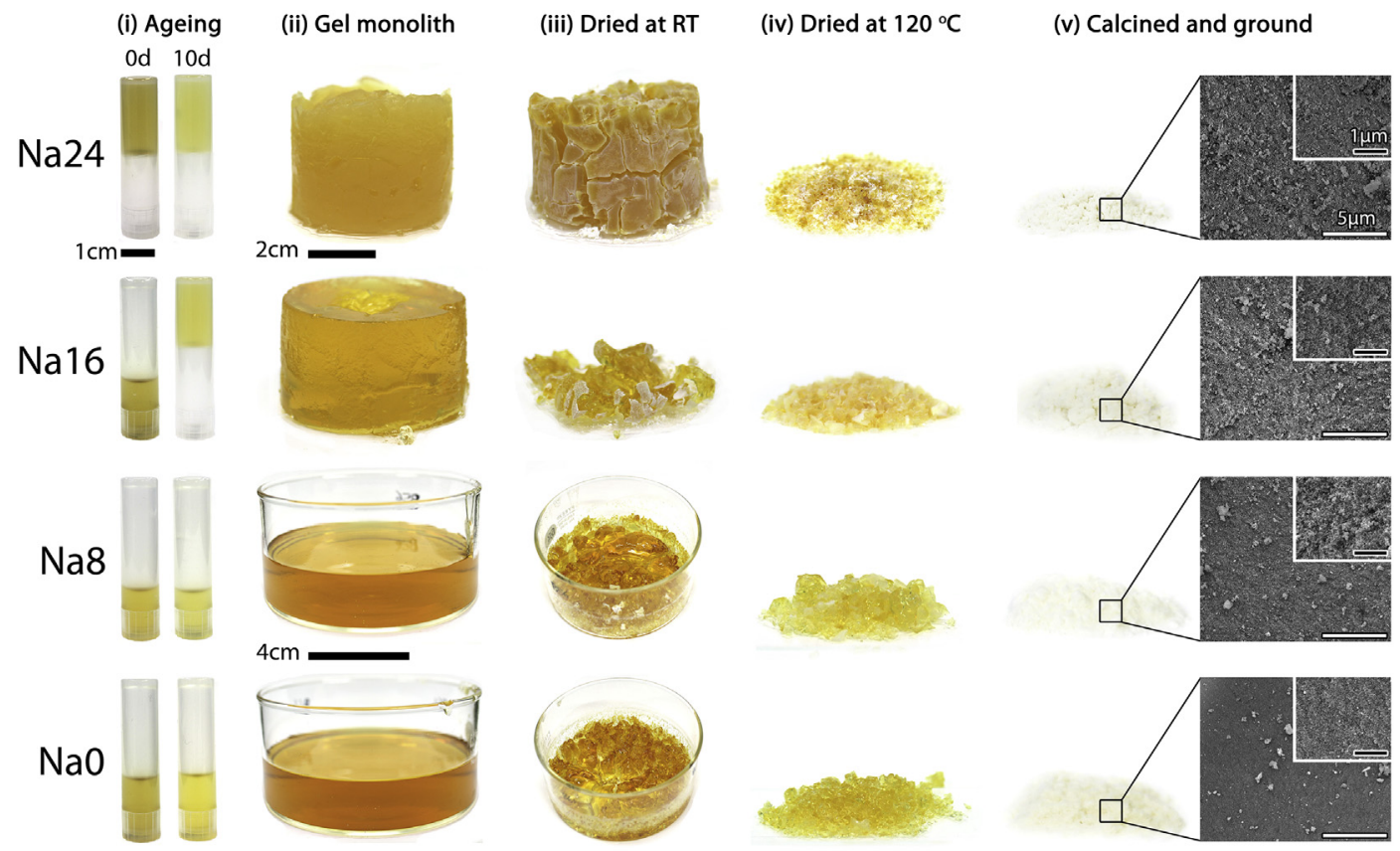

Fig. 1. An overview of the effect of sodium content on the gelling of SGBGs. (i) casting and ageing, (ii) gel monoliths at day 10, (iii) drying at RT for 1 day, (iv) drying at $120^{\circ} \mathrm{C}$ for 2 days, and (v) the final calcination at $400^{\circ} \mathrm{C}$ followed by grinding. SEM micrographs show the final nano-textured glass surface (white scale bars $=5 \mu \mathrm{m}$ and black scale bars $=1 \mu \mathrm{m})$. The amount of sodium influences the gelation behaviour, possibly due to increased $\mathrm{pH}$.

Scientific).

\subsection{Bioactivity}

Kokubo's SBF (pH 7.4) was used to examine the in vitro mineralization of the glasses [45]. Glass powder was added to sterile $50 \mathrm{~mL}$ falcon tubes containing SBF at a $1.5 \mathrm{mg} / \mathrm{mL}$ ratio and stored at $37 \pm 1{ }^{\circ} \mathrm{C}$. The vials were gently agitated twice per day to prevent agglomeration. The ability of the glasses to form HCA was examined at $0.5 \mathrm{~h}, 2 \mathrm{~h}, 6 \mathrm{~h}, 1 \mathrm{~d}, 3 \mathrm{~d}$, and $7 \mathrm{~d}$ time points where the powders were gently rinsed with deionized water then twice with anhydrous ethanol, dried overnight at room temperature, and then dried in an oven at $60^{\circ} \mathrm{C}$ for $1 \mathrm{~d}$.

\section{Results}

\subsection{Effect of sodium on processing and textural properties}

Fig. 1 provides a visual overview of the SGBG sol-gel process. While the compositions of lower sodium content did not form gels during the ageing process, $\mathrm{Na} 8$ and $\mathrm{Na} 0$ showed gel-like formation after drying at RT for $1 \mathrm{~d}$. Furthermore, Na16 formed a gel only after approximately 1 d post casting (image not shown). A summary of the glass textural properties is given in Table 2. All particles were ground to a similar median particle size $\left(D_{50}\right)$ range to directly compare their textural properties. Specific surface area values increased with decreasing sodium content, which contrasted with the pore width values which decreased with decreasing sodium content. The pore volume of each glass remained high for all glasses, but did not follow a trend with composition. SEM micrographs enabled the visualization of the nano-textured surfaces of the calcined glass powders (Fig. 1).

\section{2. structural analysis of calcined SGBGs}

SGBG bonding regions were examined using ATR-FTIR spectroscopy (Fig. 2a). Three main regions associated with borate-based glasses were identified: The $\mathrm{B}-\mathrm{O}$ stretching of the $\mathrm{BO}_{4}$ units $\left(850-1200 \mathrm{~cm}^{-1}\right)$, the $\mathrm{B}-\mathrm{O}$ stretching of the $\mathrm{BO}_{3}$ units $\left(1200-1500 \mathrm{~cm}^{-1}\right)$, and the $\mathrm{B}-\mathrm{O}-\mathrm{B}$
Table 2

Glass particle textural properties $(n=2)$ : Average Median $\left(D_{50}\right)$ and Mean $\left(D_{\text {AvG }}\right.$ ) Diameter, Specific Surface Area (SSA), Average Pore Width, and Average Pore Volume.

\begin{tabular}{|c|c|c|c|c|c|}
\hline \multicolumn{6}{|c|}{ FINAL } \\
\hline \multirow[t]{2}{*}{ ID } & \multicolumn{2}{|c|}{ Particle Size $(\mu \mathrm{m})$} & \multirow[t]{2}{*}{$\operatorname{SSA}\left(\mathrm{m}^{2} / \mathrm{g}\right)$} & \multirow{2}{*}{$\begin{array}{l}\text { Pore Width } \\
(\mathrm{nm})\end{array}$} & \multirow{2}{*}{$\begin{array}{l}\text { Pore Volume }\left(\mathrm{cm}^{3} /\right. \\
\mathrm{g})\end{array}$} \\
\hline & $\mathrm{D}_{\mathrm{AVG}}$ & $\mathrm{D}_{50}$ & & & \\
\hline $\mathrm{Na} 24$ & 44.9 & 39.2 & $91 \pm 4$ & $26 \pm 1$ & $0.75 \pm 0.01$ \\
\hline $\mathrm{Na} 16$ & 45.3 & 35.2 & $94 \pm 5$ & $22 \pm 1$ & $0.62 \pm 0.09$ \\
\hline $\mathrm{Na} 8$ & 31.0 & 29.3 & $132 \pm 11$ & $19 \pm 1$ & $0.99 \pm 0.14$ \\
\hline $\mathrm{Na} 0$ & 43.0 & 43.9 & $168 \pm 8$ & $10 \pm 0$ & $0.61 \pm 0.05$ \\
\hline
\end{tabular}

bending of the $\mathrm{BO}_{3}$ units, as indicated by the band at $\sim 720 \mathrm{~cm}^{-1}$ [46-48]. B-O stretching of boroxol rings are characteristic of the shoulder peak at $\sim 870 \mathrm{~cm}^{-1}$ and the $\mathrm{B}-\mathrm{O}$ linkages of $\mathrm{BO}_{4}$ are indicated by the broad band between $\sim 942$ and $\sim 1000 \mathrm{~cm}^{-1}$ [39, 49-51]. SGBGs with decreasing sodium content demonstrated broader, smoother spectra peaks. XRD diffractograms showed that all glasses remained amorphous after calcination, as indicated by the two broad humps after calcination at $400{ }^{\circ} \mathrm{C}$ (Fig. 2b).

\subsection{Assessment of SGBG reactivity through aqueous interactions and ion} release

As an indicator of their reactivity, DVS was used to investigate SGBG aqueous interactions by gravimetrically measuring their sorption and desorption of water vapour through direct exposure to $90 \% \mathrm{RH}$. All glasses demonstrated a rapid increase in mass within the first hour (Fig. 3a). The rate and extent of mass change after $6 \mathrm{~h}$ was dependent on composition, in which glasses with lower sodium content exhibited less $\%$ mass change. Lowering the $\mathrm{RH}$ to $0 \%$ resulted in a rapid decrease in $\%$ mass change with the higher Na containing glasses demonstrating a greater extent of mass loss. However, the overall final \% mass change was highest in glasses with the highest sodium content.

To further investigate the effect of sodium content on SGBG 

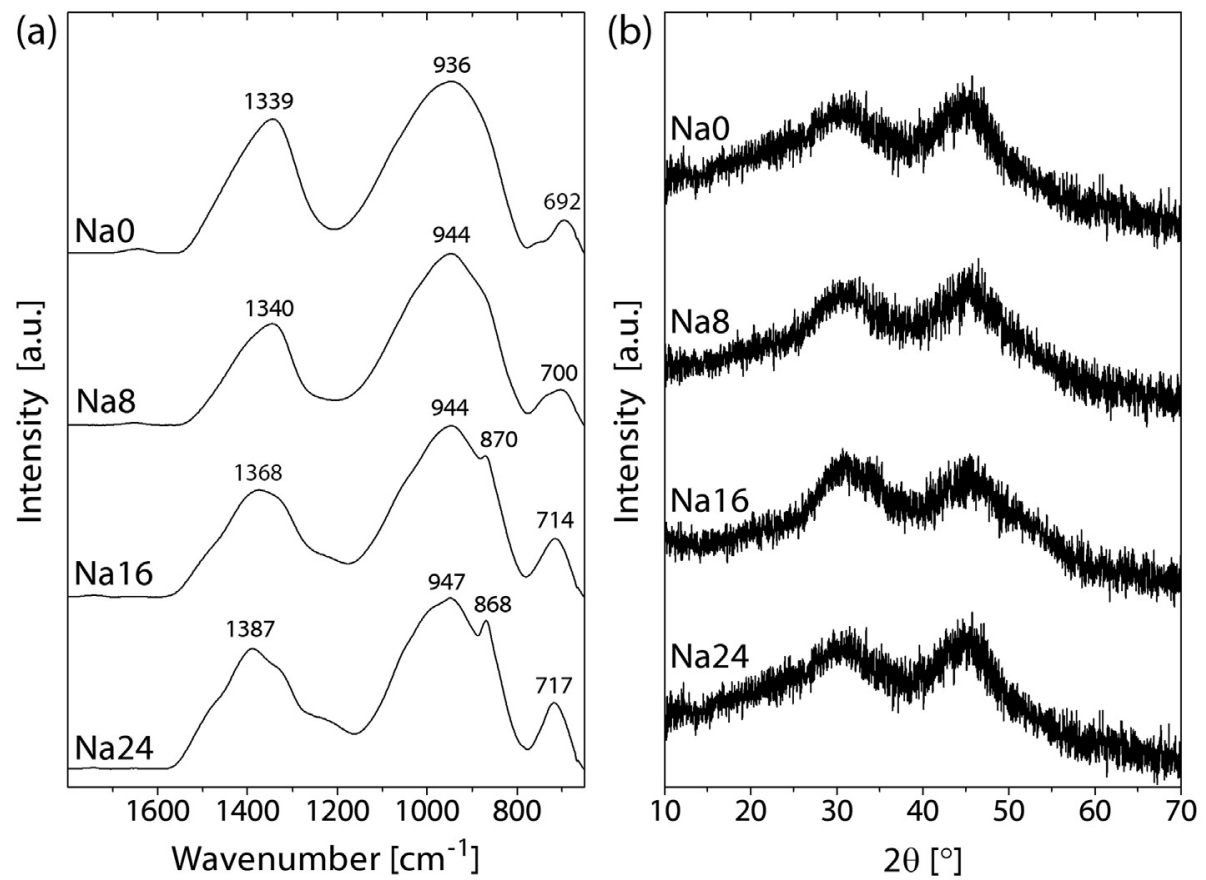

Fig. 2. Structure of the calcined SGBGs. (a) ATR-FTIR spectra, and (b) XRD diffractograms of the glass particles produced as a function of sodium content.
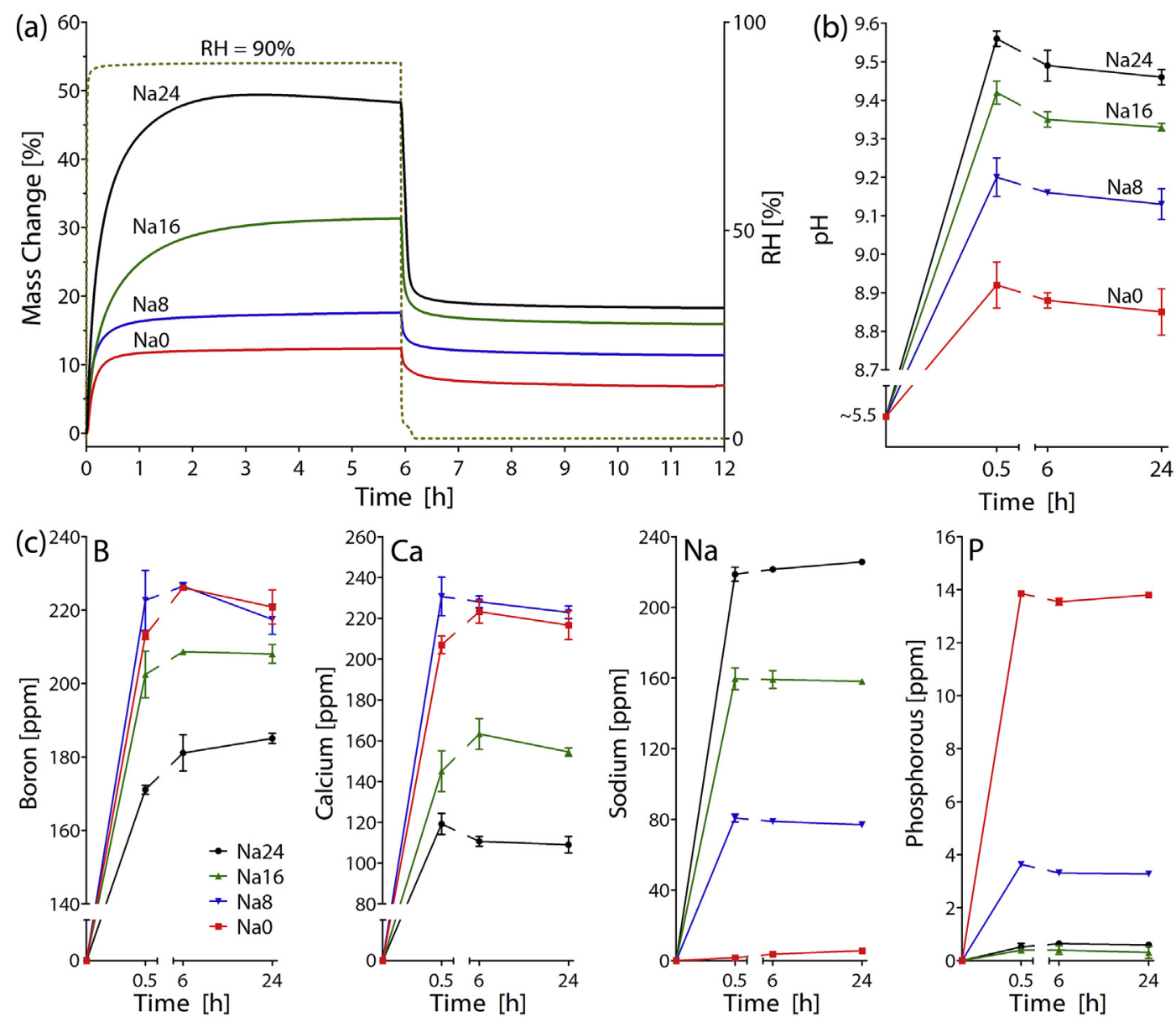

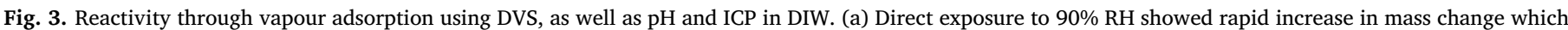

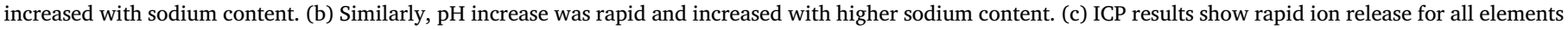
within $0.5 \mathrm{~h}$ and were dependent on composition. 
reactivity, the $\mathrm{pH}$ change and the release of boron, calcium, sodium, and phosphorous through glass dissolution in DIW were measured. All glasses exhibited a rapid increase in $\mathrm{pH}$ within $0.5 \mathrm{~h}$ that corresponded with glass sodium content (Fig. 3b). Similarly, ICP-OES (Fig. 3c) indicated that all compositions released the majority of their ions by $0.5 \mathrm{~h}$ which was previously observed with other SGBG compositions in DIW [40] and SBF [42], and the release rates stayed relatively static until 1 day. The total amounts of $\mathrm{B}$ and Ca released in the Na24 composition correspond well with previous studies [40]. Phosphate release was fairly static until $1 \mathrm{~d}$ and the rapid drop in phosphate, used as indicator for HCA formation [52] is not seen likely due to the shorter time points used. Furthermore, there was a slight decrease in calcium release from $6 \mathrm{~h}$ to $1 \mathrm{~d}$ which might indicate reprecipitation of Ca on the surface of the glass which has previously been observed [40]. Sodium release rate exhibited static release rates after $0.5 \mathrm{~h}$ based on the initial sodium content in the glass. The release rates were agreeable with the $\mathrm{pH}$ values (Fig. 3b) and DVS \% mass change (Fig. 3a).

\section{4. $S G B G$ bioactivity in $S B F$}

The ability of SGBGs to form HCA was examined up to day 7 in SBF. After $0.5 \mathrm{~h}$, ATR-FTIR spectra of all compositions indicated the formation of a phosphate peak, as shown by the strong band at $\sim 1020 \mathrm{~cm}^{-1}$ and its shoulder region at $\sim 961 \mathrm{~cm}^{-1}$, which are characteristic of the bending modes $\nu 1$ of $\mathrm{PO}_{4}{ }^{3-}$ [53] (Fig. 4). Carbonate peaks at $\sim 1470$ and $\sim 1421 \mathrm{~cm}^{-1}$ represent the stretching modes $\nu 1$ and $\nu 3$ of $\mathrm{CO}_{3}{ }^{2-}$ respectively, and a sharp peak at around $870 \mathrm{~cm}^{-1}$ indicates the bending mode $\nu 2$ of $\mathrm{CO}_{3}{ }^{2-}[54,55]$. This band at $870 \mathrm{~cm}^{-1}$ is thought to be a combination of the $\mathrm{B}-\mathrm{O}$ stretching of boroxol rings found in the calcined glasses as well as the bending mode $\nu 2$ of $\mathrm{CO}_{3}{ }^{2-}$. The $\nu 2$ bending mode of water can also be seen by the broad band at $\sim 1640 \mathrm{~cm}^{-1}[56,57]$. At longer immersion times in SBF, more defined peaks were observed, suggesting the formation of carbonated apatite.

SGBG HCA conversion was confirmed by XRD diffractograms in which hydroxyapatite-characteristic peaks, at $\sim 25$ and $\sim 32^{\circ} 2 \theta$ (".", JCPDS 9-0432) were observed in all glasses at the $2 \mathrm{~h}$ time point in SBF (Fig. 5). These broad apatite peaks, which become sharper at longer times in SBF, suggested nanometer-sized or partially crystallized HCA [7]. SEM micrographs indicated spherulitic-like HCA crystals forming at $6 \mathrm{~h}$ and become more defined at day 7 (Fig. 6).

\section{Discussion}

The importance of sodium has been long discussed with silicatebased glasses however, there has not been a systematic study on the effect of sodium in sol-gel derived borate glasses. The lack of gelation in the compositions with lower sodium ( $\mathrm{Na} 8$ and $\mathrm{Na} 0$ ) suggests that sodium may be a key component in the gelation process and that higher $\mathrm{pH}$ was needed for gel formation since the $\mathrm{pH}$ of $\mathrm{Na}$ precursor is approximately 12 . In addition, the amount of modifying oxides, $\mathrm{CaO}$ and $\mathrm{Na}_{2} \mathrm{O}$, was higher for the compositions that gelled (Table 1). Previously, it has been shown that at higher $\mathrm{pH}, \mathrm{BOH}_{4}{ }^{-}$species dominate [58] which might allow for easier gel formation since the network former exists as a four-coordinated structure, allowing for greater interconnection. The gelling behavior of $\mathrm{Na} 8$ and $\mathrm{Na} 0$ was observed to be very similar to previously reported ( $\mathrm{Na} 24)$ compositions, generated using trimethyl borate (TMB) and triethyl borate (TEB) as precursors [42], in that, evaporation during drying likely helped form the gel-like monoliths at 1d dry at RT as seen in Fig. 1. Despite these differences in gelation behavior, after calcination and grinding, all glasses became a whitish color (Fig. 1). It should also be noted that, compositionally, the ratio of network former to $\mathrm{Ca} / \mathrm{P}$ of $\mathrm{Na} 0$ is very similar to that of the first, and most commonly reported, silicate sol-gel composition " $58 \mathrm{~S}$ " (60) $\mathrm{SiO}_{2}$-(36)CaO-(4) $\mathrm{P}_{2} \mathrm{O}_{5}$ (mol\%) $[16,59]$. In terms of textural properties, the observed increase in surface area can be attributed to glasses with higher network connectivity (i.e., less network modifiers such as sodium), as previously observed with SGBGs [40] and other sol-gel systems [16].

DVS has previously been used to examine the reactivity of other bioactive glass systems based on silicate [60] and phosphate [61]. After $6 \mathrm{~h}$, the $\sim 12 \%$ mass change in $\mathrm{Na} 0$ particles $\left(\mathrm{SSA}=168 \pm 8 \mathrm{~m}^{2} / \mathrm{g}\right.$ ) was less than the $\sim 48 \%$ of the Na24 particles (SSA $=91 \pm 4 \mathrm{~m}^{2} / \mathrm{g}$ ), which demonstrated that the atomic and molecular structures, not specific surface area, have dominant roles on the chemical durability of multicomponent glasses [19, 62]. Interestingly, a similar DVS protocol on a wide range of SBGBs showed that glasses with higher sodium content experienced greater mass change despite having the lowest surface area [40]. Furthermore, in that study, a melt-quench Na24 glass equivalent resulted in $\sim 10 \%$ mass increase at $6 \mathrm{~h}$, which is in a very similar range to the final mass change of $\sim 12 \%$ observed for $\mathrm{Na} 0$ in this study. However, the SSA for the melt-quench derived glass was $0.2 \mathrm{~m}^{2}$ / $\mathrm{g}$ [40] while that of $\mathrm{NaO}$ is $168 \mathrm{~m}^{2} / \mathrm{g}$. This further demonstrates the importance of composition on the reactivity of multi-component glasses.

The increased reactivity of SGBGs is due to the higher amount of network modifiers in the glass (e.g., sodium and calcium; Table 1) leading more non-bridging oxygens in the glass structure and rendering the glass more susceptible to chemical attack [63]. However, since the amount of network former (borate) and/or the ratio of $\mathrm{Ca} / \mathrm{P}$ in the glass is not consistent throughout the compositions, it is difficult to say that
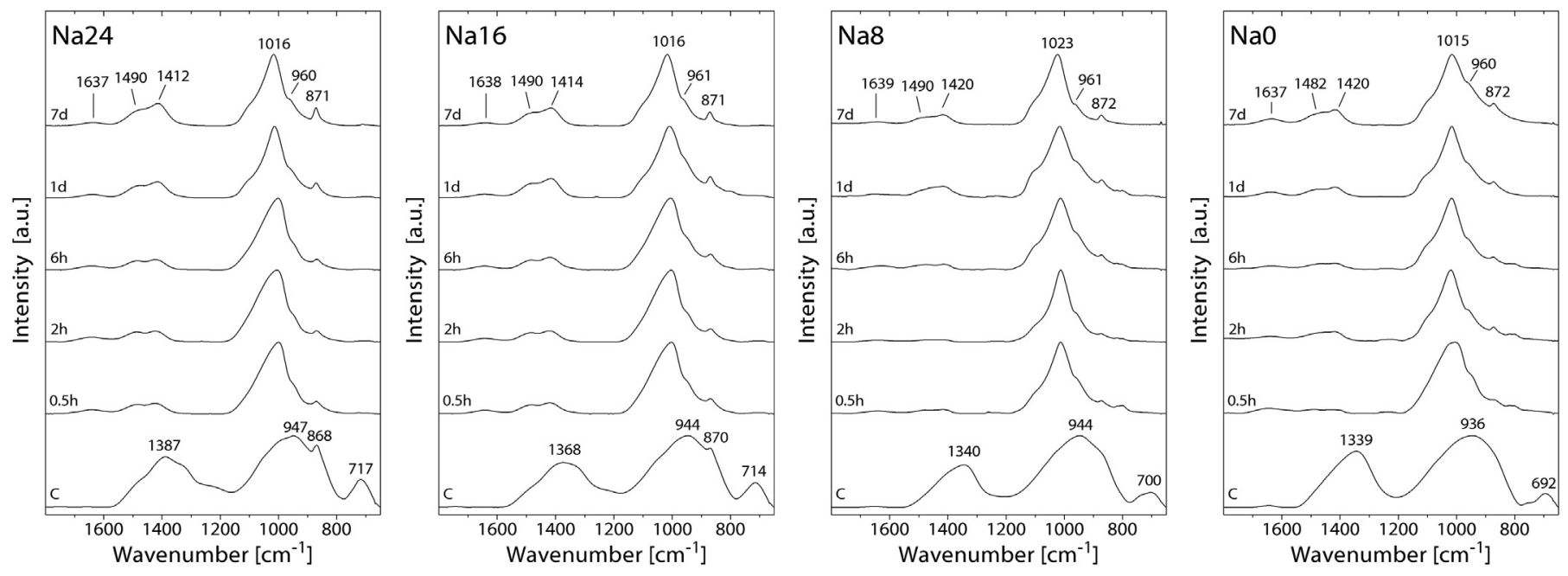

Fig. 4. ATR-FTIR spectra as a function of immersion time in SBF. Characteristic apatite-like peaks began to form after $30 \mathrm{~min}$ in SBF for all glasses. 

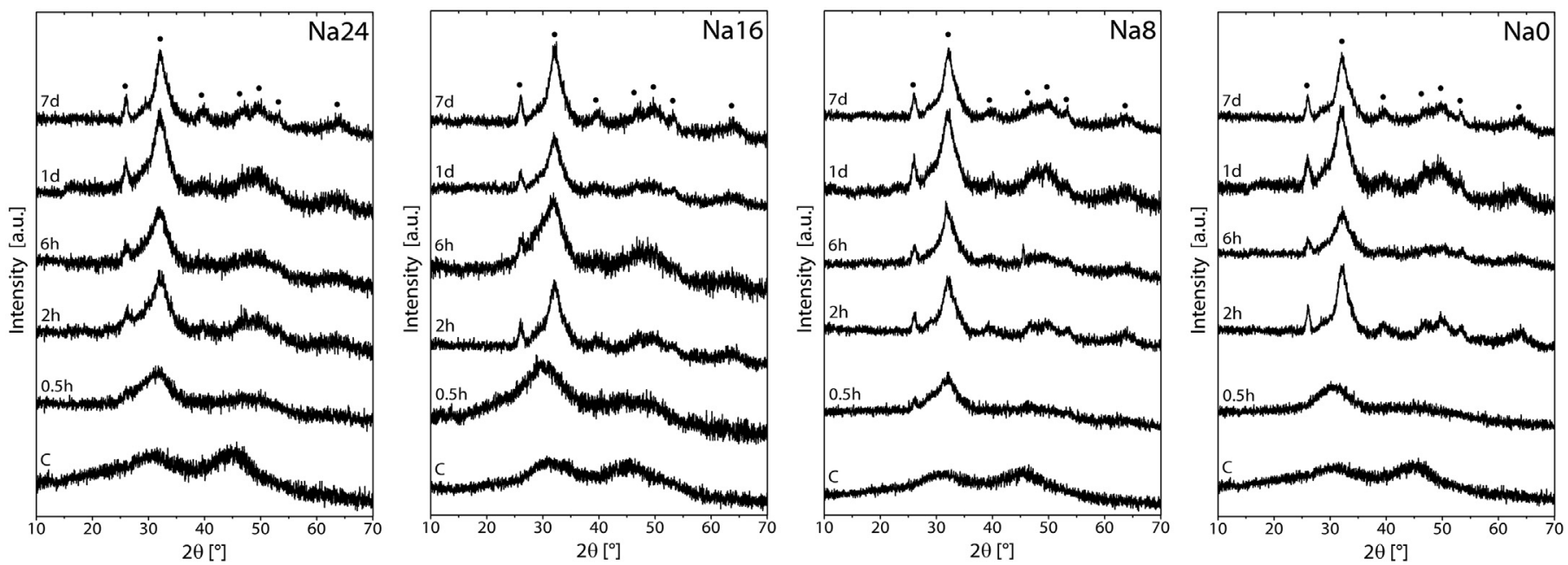

Fig. 5. XRD diffractograms as a function of immersion time in SBF. All SGBG compositions rapidly converted (within $2 \mathrm{~h}$ ) to HCA (“•”, JCPDS 9-0432).

sodium alone is responsible for this effect. It should also be noted that borate glasses do no follow a linear trend of nbo formation with the addition of network modifiers such as sodium, but rather, they demonstrate the "boron anomaly" where after a certain addition of network modifiers the glass properties begin to reverse [64]. Further studies using NMR are needed examine these effects in the current glass systems.

Previously, similar SGBG compositions exhibited the largest drop in phosphate amount in DIW [40] from $1 \mathrm{~d}$ to $3 \mathrm{~d}$ and in SBF [42] from $6 \mathrm{~h}$ to $1 \mathrm{~d}$. It is likely that the SBF accelerated the formation of HCA and if longer timepoints were used in this study then there would likely be a more significant phosphate drop. It has also been previously shown that glasses with increased sodium content led to their greater degradability since the field strength of sodium (0.18) is less than that of calcium (0.36) [65] and that the greater amount of cations in a glass the more available they are for ion exchange during dissolution [66]. This leads to a more rapid increase in $\mathrm{pH}$, which was previously observed with SGBGs [40] along with bioactive silicate-glasses [67], and likely is responsible for in the increased reactivity according to DVS. However, with the simplified composition of $\mathrm{Na} 0$, the $\mathrm{pH}$ rise was not as high
(Fig. 3b). This composition might be more beneficial for future tissue engineering applications since, typically, high $\mathrm{pH}$ values lead to cell death in vitro $[66,68]$. It has also been demonstrated in vivo that sodium free silicate glasses are biocompatible and osteoconductive [69] and low sodium $\left(6 \mathrm{~mol} \% \mathrm{Na}_{2} \mathrm{O}\right)$ borate glass are osteoconductive and osseointegrative [70].

Taken together, this study demonstrated that, while sodium inclusion impacted the processing and reactivity, the bioactivity was not largely affected by its presence in these glass systems. A similar finding recently found in melt-derived silicate systems [71]. However, it should be noted that while the sodium content was decreased, the calcium and phosphate contents and ratios were increased, both of which are known to contribute to bioactivity [19]. Therefore, further investigations with fixed borate content and/or $\mathrm{Ca} / \mathrm{P}$ ratio are needed to observe the direct role of sodium in SGBGs.

\section{Conclusions}

A new range of sol-gel derived bioactive borate glasses with decreasing sodium content have been created. Lower amounts of sodium
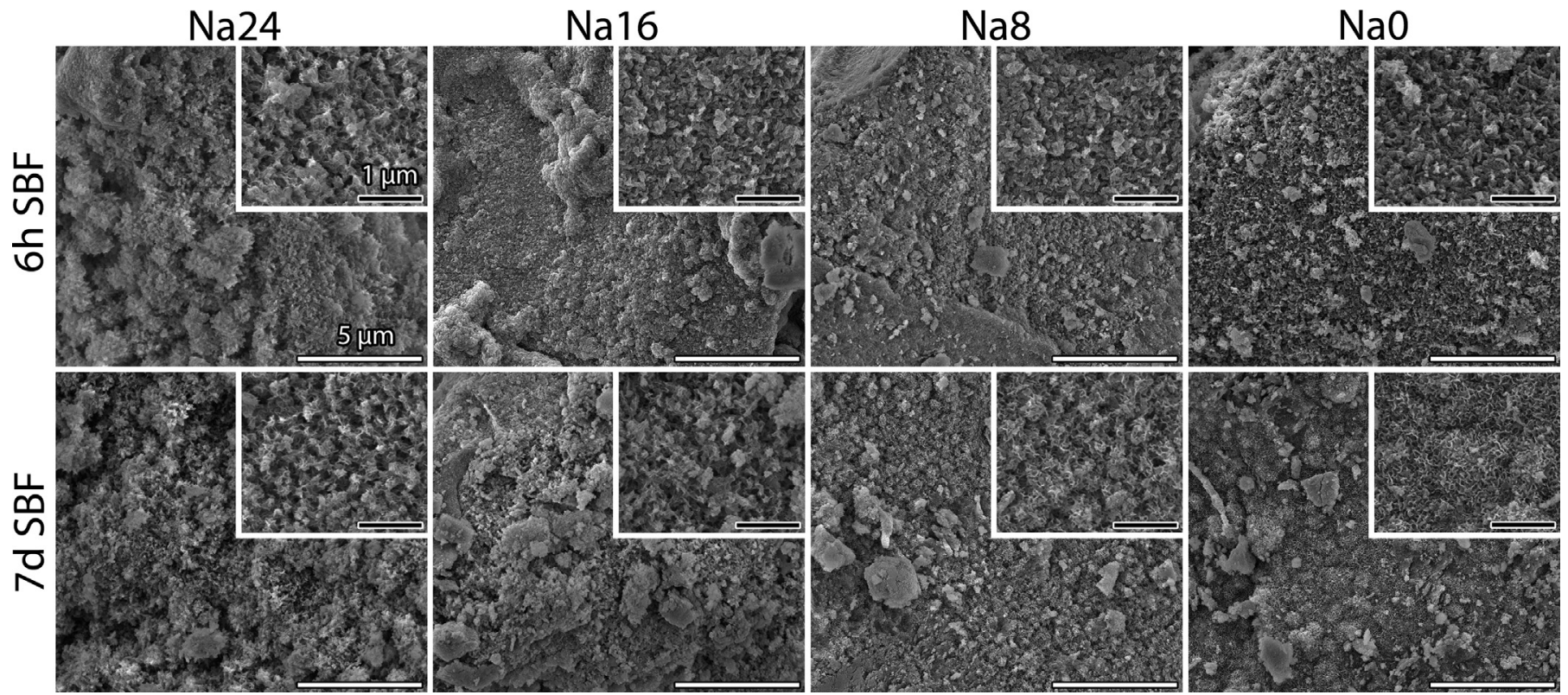

Fig. 6. SEM micrographs of the glasses after immersion in SBF for $6 \mathrm{~h}$ and $7 \mathrm{~d}$. Typical HCA crystals begin to form at $6 \mathrm{~h}$ and become more defined at $7 \mathrm{~d}$ for all glasses (white scale bars $=5 \mu \mathrm{m}$ and black scale bars $=1 \mu \mathrm{m}$ ). 
limited gel formation but did not induce crystallization as observed in other sol-gel systems. Furthermore, glasses with less sodium had higher specific surface areas. Reactivity, in terms of DVS and $\mathrm{pH}$, increased with increasing sodium content. Ion release of each element was rapid and stayed static until the $1 \mathrm{~d}$ timepoint with some elements such as calcium, demonstrating a slightly decreasing trend suggesting reprecipitation. However, the bioactivity of the SGBGs did not appear to be affected by sodium content or release profile, as all glasses demonstrated rapid HCA conversion in SBF within $2 \mathrm{~h}$ and according to XRD. The study represents a step towards simplified, three-component SGBGs for tissue engineering applications.

\section{Acknowledgements}

This study was supported by Canada NSERC, Québec MEIE, CFI and McGill University Faculty of Engineering Hatch Faculty Fellowship for S.N.N. W.C.L. is supported by the McGill Engineering Innovation Fellowship and FQRNT - Nature et Technologies Bourses de doctorat en recherché. Prof. Kristian Waters is thanked for use of the DVS and Ranjan Roy is thanked for assistance with the ICP.

\section{References}

[1] L.L. Hench, The story of bioglass ${ }^{\oplus}$, J. Mater. Sci. Mater. Med. 17 (2006) 967-978.

[2] J.R. Jones, D.S. Brauer, L. Hupa, D.C. Greenspan, Bioglass and bioactive glasses and their impact on healthcare, Int. J. Appl. Glas. Sci. 7 (2016) 423-434.

[3] L.L. Hench, Bioceramics - from concept to clinic, J. Am. Ceram. Soc. 74 (1991) $1487-1510$

[4] V. Miguez-Pacheco, L.L. Hench, A.R. Boccaccini, Bioactive glasses beyond bone and teeth: emerging applications in contact with soft tissues, Acta Biomater. 13 (2015) $1-15$.

[5] L.L. Hench, R.J. Splinter, W.C. Allen, T.K. Greenlee, Bonding mechanisms at the interface of ceramic prosthetic materials, J. Biomed. Mater. Res. 5 (1971) 117-141.

[6] A. Yao, D. Wang, W. Huang, Q. Fu, M.N. Rahaman, D.E. Day, In vitro bioactive characteristics of borate-based glasses with controllable degradation behavior, J. Am. Ceram. Soc. 90 (2006) 303-306.

[7] W. Huang, D.E. Day, K. Kittiratanapiboon, M.N. Rahaman, Kinetics and mechanisms of the conversion of silicate (45S5), borate, and borosilicate glasses to hydroxyapatite in dilute phosphate solutions, J. Mater. Sci. Mater. Med. 17 (2006) 583-596.

[8] Q. Fu, M.N. Rahaman, H. Fu, X. Liu, Silicate, borosilicate, and borate bioactive glass scaffolds with controllable degradation rate for bone tissue engineering applications. I. Preparation and in vitro degradation, J. Biomed. Mater. Res. A 95 (2010) 164-171.

[9] A. Abdelghany, H. Elbatal, F. EzzElDin, Bone bonding ability behavior of some ternary borate glasses by immersion in sodium phosphate solution, Ceram. Int. 38 (2012) 1105-1113.

[10] D. Day, J. White, R. Brown, K. McMenamin, Transformation of borate glasses into biologically useful materials, Glass Technol. Eur. J. Glass Sci. Technol. Part A 44 (2003) 75-81.

[11] X. Han, D.E. Day, Reaction of sodium calcium borate glasses to form hydroxyapatite, J. Mater. Sci. Mater. Med. 18 (2007) 1837-1847.

[12] Y. Lin, R.F. Brown, S.B. Jung, D.E. Day, Angiogenic effects of borate glass microfibers in a rodent model, J. Biomed. Mater. Res. A 102 (12) (2014) 4491-4499.

[13] X. Liu, M.N. Rahaman, D.E. Day, Conversion of melt-derived microfibrous borate (13-93B3) and silicate (45S5) bioactive glass in a simulated body fluid, J. Mater. Sci. Mater. Med. 24 (2013) 583-595.

[14] P. Wray, Cotton candy'that heals? Am. Ceram. Soc. Bull. 90 (2011) 25-29.

[15] S. Zhao, L. Li, H. Wang, Y. Zhang, X. Cheng, N. Zhou, M.N. Rahaman, Z. Liu, W. Huang, C. Zhang, Wound dressings composed of copper-doped borate bioactive glass microfibers stimulate angiogenesis and heal full-thickness skin defects in a rodent model, Biomaterials 53 (2015) 379-391.

[16] R. Li, A. Clark, L. Hench, An investigation of bioactive glass powders by sol-gel processing, J. Appl. Biomater. 2 (1991) 231-239.

[17] L.L. Hench, J.K. West, The sol-gel process, Chem. Rev. 90 (1990) 33-72.

[18] P. Sepulveda, J.R. Jones, L.L. Hench, Characterization of melt-derived $45 \mathrm{~S} 5$ and solgel-derived 58 S bioactive glasses, J. Biomed. Mater. Res. 58 (2001) 734-740.

[19] J.R. Jones, Review of bioactive glass-from Hench to hybrids, Acta Biomater. 9 (1) (2012) 4457-4486.

[20] G.J. Owens, R.K. Singh, F. Foroutan, M. Alqaysi, C.-M. Han, C. Mahapatra, H.W. Kim, J.C. Knowles, Sol-gel based materials for biomedical applications, Prog. Mater. Sci. 77 (2016) 1-79.

[21] Q.-Z. Chen, Y. Li, L.-Y. Jin, J.M. Quinn, P.A. Komesaroff, A new sol-gel process for producing Na 2 O-containing bioactive glass ceramics, Acta Biomater. 6 (2010) 4143-4153.

[22] M.S. Bahniuk, H. Pirayesh, H.D. Singh, J.A. Nychka, L.D. Unsworth, Bioactive glass 4555 powders: effect of synthesis route and resultant surface chemistry and crystallinity on protein adsorption from human plasma, Biointerphases 7 (2012) 1-15.

[23] H. Pirayesh, J.A. Nychka, Sol-gel synthesis of bioactive glass-ceramic 4555 and its in vitro dissolution and mineralization behavior, J. Am. Ceram. Soc. 96 (2013) 1643-1650.

[24] H.C. Li, D.G. Wang, J.H. Hu, C.Z. Chen, Crystallization, mechanical properties and in vitro bioactivity of sol-gel derived $\mathrm{Na} 2 \mathrm{O}-\mathrm{CaO}-\mathrm{SiO} 2-\mathrm{P} 2 \mathrm{O} 5$ glass-ceramics by partial substitution of CaF2 for CaO, J. Sol-Gel Sci. Technol. 67 (2013) 56-65.

[25] K. Zheng, A. Solodovnyk, W. Li, O.M. Goudouri, C. Stähli, S.N. Nazhat, A.R. Boccaccini, Aging time and temperature effects on the structure and bioactivity of gel-derived 4555 glass-ceramics, J. Am. Ceram. Soc. 98 (2015) 30-38.

[26] J. Faure, R. Drevet, A. Lemelle, N.B. Jaber, A. Tara, H. El Btaouri, H. Benhayoune, A new sol-gel synthesis of $45 \mathrm{~S} 5$ bioactive glass using an organic acid as catalyst, Mater. Sci. Eng. C 47 (2015) 407-412.

[27] R.L. Siqueira, O. Peitl, E.D. Zanotto, Gel-derived SiO2-CaO-Na2O-P2O5 bioactive powders: synthesis and in vitro bioactivity, Mater. Sci. Eng. C 31 (2011) 983-991.

[28] R.L. Siqueira, L.C. Costa, M.A. Schiavon, D.T. de Castro, A.C. dos Reis, O. Peitl, E.D. Zanotto, Bioglass ${ }^{\circledast}$ and resulting crystalline materials synthesized via an acetic acid-assisted sol-gel route, J. Sol-Gel Sci. Technol. (2017) 1-9.

[29] I. Cacciotti, M. Lombardi, A. Bianco, A. Ravaglioli, L. Montanaro, Sol-gel derived 45S5 bioglass: synthesis, microstructural evolution and thermal behaviour, J. Mater. Sci. Mater. Med. 23 (2012) 1849-1866.

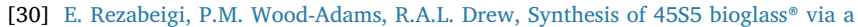
straightforward organic, nitrate-free sol-gel process, Mater. Sci. Eng. C 40 (2014) $248-252$.

[31] R. Ota, N. Asagi, J. Fukunaga, N. Yoshida, T. Fujii, Variation of the gel region with heat-treatment in the $\mathrm{B} 2 \mathrm{O} 3-\mathrm{Na} 2 \mathrm{O}-\mathrm{TiO} 2$ system compared with the melt-quenched glass region, J. Mater. Sci. 25 (1990) 4259-4265.

[32] G. Krüner, G. Frischat, Some properties of n-containing lithium borate glasses prepared by different sol-gel methods, J. Non-Cryst. Solids 121 (1990) 167-170.

[33] A. Irwin, J. Holmgren, T. Zerda, J. Jonas, Spectroscopic investigations of borosiloxane bond formation in the sol-gel process, J. Non-Cryst. Solids 89 (1987) 191-205.

[34] M.C. Weinberg, G.F. Neilson, G.L. Smith, B. Dunn, G. Moore, J. Mackenzie, The preparation and characterization of a lithium borate glass prepared by the gel technique, J. Mater. Sci. 20 (1985) 1501-1508.

[35] N. Tohge, J. Mackenzie, Preparation of 20Na2O-80B2O3 glasses by sol-gel method, J. Non-Cryst. Solids 68 (1984) 411-418.

[36] R.L. Ciceo, D.-L. Trandafir, T. Radu, O. Ponta, V. Simon, Synthesis, characterisation and in vitro evaluation of sol-gel derived SiO2-P2O5-CaO-B2O3 bioactive system, Ceram. Int. 40 (2014) 9517-9524.

[37] H.C. Li, D.G. Wang, J.H. Hu, C.Z. Chen, Effect of the partial substitution of K2O, $\mathrm{MgO}, \mathrm{B} 2 \mathrm{O} 3$ for $\mathrm{CaO}$ on crystallization, structure and properties of Na2O-CaO-SiO2-P2O5 system glass-ceramics, Mater. Lett. 106 (2013) 373-376.

[38] D. Carta, J.C. Knowles, P. Guerry, M.E. Smith, R.J. Newport, Sol-gel synthesis and structural characterisation of P2O5-B2O3-Na2O glasses for biomedical applications, J. Mater. Chem. 19 (2009) 150-158.

[39] D. Carta, D. Qiu, P. Guerry, I. Ahmed, E.A. Abou Neel, J.C. Knowles, M.E. Smith, R.J. Newport, The effect of composition on the structure of sodium borophosphate glasses, J. Non-Cryst. Solids 354 (2008) 3671-3677.

[40] W.C. Lepry, S.N. Nazhat, Highly bioactive sol-gel-derived borate glasses, Chem. Mater. 27 (2015) 4821-4831.

[41] J. Ning, A. Yao, D. Wang, W. Huang, H. Fu, X. Liu, X. Jiang, X. Zhang, Synthesis and in vitro bioactivity of a borate-based bioglass, Mater. Lett. 61 (2007) 5223-5226.

[42] W.C. Lepry, S. Naseri, S.N. Nazhat, Effect of processing parameters on textural and bioactive properties of sol-gel-derived borate glasses, J. Mater. Sci. (2017) 1-13.

[43] S. Brunauer, P.H. Emmett, E. Teller, Adsorption of gases in multimolecular layers, J. Am. Chem. Soc. 60 (1938) 309-319.

[44] L.G. Joyner, E.P. Barrett, R. Skold, The determination of pore volume and area distributions in porous substances. II. Comparison between nitrogen isotherm and mercury Porosimeter methods, J. Am. Chem. Soc. 73 (1951) 3155-3158.

[45] T. Kokubo, H. Takadama, How useful is SBF in predicting in vivo bone bioactivity? Biomaterials 27 (2006) 2907-2915.

[46] E. Kamitsos, M. Karakassides, G.D. Chryssikos, A vibrational study of lithium borate glasses with high Li2O content, Phys. Chem. Glasses 28 (1987) 203-209.

[47] A.M. Deliormanll, In vitro assessment of degradation and bioactivity of robocast bioactive glass scaffolds in simulated body fluid, Ceram. Int. 38 (2012) 6435-6444.

[48] E. Kamitsos, M. Karakassides, G.D. Chryssikos, Vibrational spectra of magnesiumsodium-borate glasses. 2. Raman and mid-infrared investigation of the network structure, J. Phys. Chem. 91 (1987) 1073-1079.

[49] C. Gautam, A.K. Yadav, A.K. Singh, A review on infrared spectroscopy of borate glasses with effects of different additives, ISRN Ceram. 2012 (2012).

[50] S. Agathopoulos, D. Tulyaganov, J. Ventura, S. Kannan, M. Karakassides, J. Ferreira, Formation of hydroxyapatite onto glasses of the CaO-MgO-SiO2 system with B2O3, Na2O, CaF2 and P2O5 additives, Biomaterials 27 (2006) 1832-1840.

[51] L. Balachandera, G. Ramadevudub, M. Shareefuddina, R. Sayannac, Y. Venudharc, IR analysis of borate glasses containing three alkali oxides, ScienceAsia 39 (2013) 278-283.

[52] A.L.B. Maçon, T.B. Kim, E.M. Valliant, K. Goetschius, R.K. Brow, D.E. Day, A. Hoppe, A.R. Boccaccini, I.Y. Kim, C. Ohtsuki, T. Kokubo, A. Osaka, M. ValletRegí, D. Arcos, L. Fraile, A.J. Salinas, A.V. Teixeira, Y. Vueva, R.M. Almeida, M. Miola, C. Vitale-Brovarone, E. Verné, W. Höland, J.R. Jones, A unified in vitro evaluation for apatite-forming ability of bioactive glasses and their variants, J. Mater. Sci. Mater. Med. 26 (2015) 1-10.

[53] C. Rey, M. Shimizu, B. Collins, M.J. Glimcher, Resolution-enhanced fourier transform infrared spectroscopy study of the environment of phosphate ion in the early deposits of a solid phase of calcium phosphate in bone and enamel and their evolution with age: 2 . Investigations in the nu3PO4 domain, Calcif. Tissue Int. 49 (1991) 383-388. 
[54] D. Nelson, J. Featherstone, Preparation, analysis, and characterization of carbonated apatites, Calcif. Tissue Int. 34 (1981) S69-S81.

[55] N. Chickerur, M. Tung, W. Brown, A mechanism for incorporation of carbonate into apatite, Calcif. Tissue Int. 32 (1980) 55-62.

[56] R.Z. Legeros, The unit-cell dimensions of human enamel apatite: effect of chloride incorporation, Arch. Oral Biol. 20 (1975) 63-71.

[57] B. Fowler, E. Moreno, W. Brown, Infra-red spectra of hydroxyapatite, octacalcium phosphate and pyrolysed octacalcium phosphate, Arch. Oral Biol. 11 (1966) 477-492.

[58] C.J. Brinker, G.W. Scherer, Sol-Gel Science: The Physics and Chemistry of Sol-Gel Processing, Academic press, 1990.

[59] J. Ma, C. Chen, D. Wang, X. Meng, J. Shi, Influence of the sintering temperature on the structural feature and bioactivity of sol-gel derived SiO 2-CaO-P 2 O 5 bioglass, Ceram. Int. 36 (2010) 1911-1916.

[60] S. Naseri, W.C. Lepry, W. Li, K.E. Waters, A.R. Boccaccini, S.N. Nazhat, 45S5 bioactive glass reactivity by dynamic vapour sorption, J. Non-Cryst. Solids 432 (Part A) (2016) 47-52.

[61] C. Stähli, M. Shah Mohammadi, K.E. Waters, S.N. Nazhat, Characterization of aqueous interactions of copper-doped phosphate-based glasses by vapour sorption, Acta Biomater. 10 (2014) 3317-3326.

[62] A. Tilocca, Structural models of bioactive glasses from molecular dynamics simulations, Proc. R. Soc. A 465 (2009) 1003-1027.

[63] A.N. Cormack, The Structure of Bioactive Glasses and their Surfaces, Bio-Glasses,
John Wiley \& Sons, Ltd, 2012, pp. 65-74.

[64] A.C. Wright, My borate life: an enigmatic journey, Int. J. Appl. Glas. Sci. 6 (2015) 45-63.

[65] G. Brown, F. Farges, G. Calas, X-ray scattering and X-ray spectroscopy studies of silicate melts, Rev. Mineral. Geochem. 32 (1995) 317-410.

[66] K. Wallace, R. Hill, J. Pembroke, C. Brown, P. Hatton, Influence of sodium oxide content on bioactive glass properties, J. Mater. Sci. Mater. Med. 10 (1999) 697-701.

[67] J.R. Jones, P. Sepulveda, L.L. Hench, Dose-dependent behavior of bioactive glass dissolution, J. Biomed. Mater. Res. A 58 (2001) 720-726.

[68] I. Kansal, A. Reddy, F. Muñoz, S.-J. Choi, H.-W. Kim, D.U. Tulyaganov, J.M. Ferreira, Structure, biodegradation behavior and cytotoxicity of alkali-containing alkaline-earth phosphosilicate glasses, Mater. Sci. Eng. C 44 (2014) 159-165.

[69] P.P. Cortez, A.F. Brito, S. Kapoor, A.F. Correia, L.M. Atayde, P. Dias-Pereira, A.C. Maurício, A. Afonso, A. Goel, J.M. Ferreira, The in vivo performance of an alkali-free bioactive glass for bone grafting, $\mathrm{F}$ ast $\mathrm{O} \mathrm{s}^{\oplus} \mathrm{BG}$, assessed with an ovine model, J. Biomed. Mater. Res. B 105 (2017) 30-38.

[70] K. O'Connell, C. Pierlot, H. O'Shea, D. Beaudry, M. Chagnon, M. Assad, D. Boyd, Host responses to a strontium releasing high boron glass using a rabbit bilateral femoral defect model, J. Biomed. Mater. Res. B 105 (2017) 1818-1827.

[71] C. Xiaojing, C. Xiaohui, D.S. Brauer, R.M. Wilson, R.V. Law, R.G. Hill, K. Natalia, Sodium is not essential for high bioactivity of glasses, Int. J. Appl. Glas. Sci. 8 (2017) 428-437. 